\title{
WHAT ARE NEW DEVELOPMENTS IN THE EVALUATION OF SECONDARY SCHOOLS?
}

Chairman: George E. Erickson, Principal, High School, Beaverton, Oregon.

\section{DiscussanTs:}

I. B. Bryant, Principal, Kashmere Gardens High School, Houston, Texas.

Wendell E. Dunn, Principal, Forest Park High School, Baltimore, Maryland.

\section{Summary of the presentation made by KENT W. LEACH}

Tre

HERE are relatively few new developments in the evaluation of secondary schools. There are a few different techniques of evaluation and there are slightly altered interpretations of philosophy concerning the evaluative process. But there is really nothing genuinely new-only modifications of common sense, an ingredient which is not innate in human beings, but rather an end product of the blending of practice and theory.

Evaluation is the process of ascertaining whether or not something has value, and if it has, to what degree. In order to determine the degree of value, "yardsticks" or criteria should be used as a guide to determine whether or not the characteristics of value exist. Before such criteria can be formulated, a philosophy should have been formulated; and a philosophy should imply goals or objectives. To determine whether or not there are new developments in the evaluation of secondary schools, one must ask whether or not there is anything new concerning the formulation of philosophy, the development of objectives, the establishment of criteria, and the use of techniques in the process of evaluating.

\section{The PhILosophy}

At one time administrators, teachers, and the community used philosophies that were rather common to all communities. No one knew exactly from whence they came. Perhaps they were derived from the speeches and writings of educators and authors. At any rate, each school simply followed an installed philosophy. The philosophy existed before the school was established and the school had to fit the philosophy.

A change gradually developed until it was believed that schools should be evaluated in terms of their own unique problems and backgrounds. This attitude held forth that each school had unique problems, unique individuals, and unique situations. Therefore, it should be evaluated in terms of its own unique philosophy. A major weakness with this approach,

Kent W. Leach is Associate Professor in the School of Education and Director of the Bureau of School Services, University of Michigan, Ann Arbor, Michigan. 
however, was that there was not an adequate amount of research done to determine the kinds of uniqueness. As a result, a different viewpoint was developed; it was advocated that a thorough survey should be made of the school's community and the entire environment in which the school was located and which the school served. Knowing all about the community would enable a school to formulate a philosophy which would help meet the needs of the community and the pupils living in the community. However, the thinking now is to have a combination of the above listed procedures. It is realized that parts of the philosophy of a school should be indeed scrutinized in terms of the kind of community which the school serves; but there should also be some parts of the philosophy of a school which should be in the philosophies of all schools, no matter in what types of communities the schools exist. After all, although unique differences of communities should be recognized, there are also some common objectives toward which all schools should strive. This attitude implies much. It means, for instance, that secondary-school curricula should offer programs of instruction which meet not only the needs of pupils in a community, but which also prepare its pupils to compete successfully with other people from other parts of the world. It implies, further, that an education which helps to adjust an individual to his local environment is not sufficient, because the community in which a pupil may find himself after his formal schooling has been completed may be located in another part of the world.

\section{The OBJectives}

Actually, the objectives of secondary education have not changed very much over the last twenty years. The often quoted phrase "meeting the needs of children" is gradually becoming closer to becoming a reality. Despite recurrent attempts to have secondary education meet the needs of just a few pupils, the intellectually "elite," or the college bound, more and more secondary schools are developing a comprehensive high-school program-a program which helps all pupils. Even though the concept of public schools is being questioned and attacked in certain parts of the country and even though some self-appointed "authorities" are formulating objectives for secondary education, the general public is demanding, and demanding with increasing frequency, that the public schools be for all boys and girls and not for just a select few.

\section{The Criteria}

What "yardsticks" can be used as guides to help evaluators determine whether or not secondary schools are functioning in terms of their philosophy and objectives? As Dr. Roderick D. Matthews points out, the Evaluative Criteria published by the Cooperative Study of SecondarySchool Standards is contributing, among many other things, the lists of different kinds of criteria for an excellent secondary school. The continuing revisions of this document do present us with excellent criteria. 


\section{Techniques of Evaluating}

Are there new techniques which evaluators can use to determine whether or not a secondary school is doing a good job? The state of Michigan has something to offer in the unique relationship that exists between the state-wide accrediting of schools as done by the University of Michigan and the regional accrediting of schools as carried on by the North Central Association of Colleges and Secondary Schools. There is nothing new, of course, in having an evaluation of schools made via an examination of annual report blanks filled out by schools describing certain phases of the school's program, qualifications of teachers, class enrollments, etc. This, of course, is done in Michigan as well as in other states. There is nothing new, either, in having those schools that are applying for accreditation from either the state agency or the North Central Association visited by an evaluating team. But the unique feature that exists in Michigan is that accrediting is viewed by the schools as being an evaluation of the entire school and its program. Accrediting is not a process that simply checks the academic offerings of college bound students with the purpose of permitting them to enter universities and colleges without taking entrance examinations. During the last ten years, the accrediting of secondary schools in Michigan by the University of Michigan and the North Central Association is an evaluation of all facets of the secondary school.

Whereas in many states schools are visitied by an evaluation team only when they are applying for accrediting or subsequently when extreme problems emerge, secondary schools in Michigan are visited regularly. Schools meeting the University of Michigan's minimum criteria are visited every two years; schools meeting the University of Michigan's highest criteria use the North Central Association's criteria and are visited every four years. Of the 835 secondary schools, public and non-public, in the state of Michigan, 673 are accredited by the University of Michigan, 280 of which are accredited by the North Central Association. All of these 673 schools are visited regularly by Universitiy of Michigan personnel. Data collected by University of Michigan personnel during the visits are made available to the University's Executive Committee and to the North Centrail Association's State Committee. Thus, both agencies have continual up-to-date files on all accredited secondary schools in Michigan.

What process does the University of Michigan use in sending out evaluation teams to the schools? Schools with an enrollment of 200 or less are usually visited by one person who spends the entire day in the school meeting with the administrators, obtaining a bird's-eye view of the entire building and site, talking with teachers individually, and seeing every room in the building. After school, the visitor meets with the entire staff.

Schools with enrollments between 200-500 are usually visited by teams made up of two to five people. In addition to the general consultant in charge of the visit (one who has had administrative and teaching experience in public schools), the other personnel are University faculty mem- 
bers representing those areas of the curriculum in which local administrators desire help. After school the University specialists meet with teachers in various groups.

Schools with enrollments over 500 are visited by teams numbering from six to sixteen people. The procedures are the same as outlined above. After all visits, a letter citing the observations of the visitors is sent back to the school and carbons are available to the University of Michigan's Executive Committee and the NCA's State Committee. The main features of the above listed procedures are these:

1. Regularly scheduled "on the scene" visits are made to schools by qualified people.

2. Physical features of the school are checked.

3. The administrative and organizational features of the school are scrutinized.

4. The special phases of the school's program are checked; e.g., library, guidance, testing, lunch program, extra or cocurricular activities, etc.

5. The academic and non-academic segments of the instructional program are checked by subject area specialists.

Recently, principals of secondary schools as well as outstanding secondary-school teachers have been serving with University of Michigan personnel on some of the evaluation teams. Accreditation and evaluation in Michigan are now terms that are synonymous; and the important point to administrators is that evaluation is truly a continual process.

By using the Evaluative Criteria as a guide, by using the subjective judgments of subject matter specialists, and by using the accreditation criteria of the University of Michigan and the North Central Association, the local administrator and his teaching staff obtain ideas which can be used as points of discussion in staff meetings. As a result, the school's staff members are usually stimulated to evaluate their own school.

Evaluation of a secondary school should be more than the scanning of a report blank; regularly scheduled visits to the school should be made by qualified people. Finding out what is valuable about a school requires the use of more than a set of standards; it demands, also, a compilation of subjective judgments. Printed regulations, listed policies, and published criteria supplemented by the observations of qualified people-when all of these forces are brought into play, the chances for a valid evaluation exist. 


\section{Summary of the presentation made by RODERIC D. MATTHEWS}

$\mathrm{M}$

ANY suggestions have been made relative to the evaluation of secondary schools, but there is growing support for the use of the procedures and materials of the Cooperative Study of Secondary School Standards. The findings of several research studies indicate the value and effectiveness of these procedures and the increase in sales of the materials are proof of their growing popularity. Although much has been said and written about the Cooperative Study of Secondary School Standards, requests for explanations and information seem on the increase.

Early in the work of the Cooperative Study, the principle was developed that a school can best be evaluated in relation to what it is trying to do (philosophy and objectives) for the pupils which it enrolls or for the pupils for which it has responsibility. One may criticize the philosophy and raise questions about the knowledge of the characteristics and needs of the youth served by the school, but it is difficult to see how it is fair or appropriate to judge the quality of what is done in a school on the basis of goals not accepted by those responsible for the school or on the basis of ability or needs of students not present in the school or not available to the school. The materials which have been developed to make possible the type of evaluation recommended by the Cooperative Study are provided in the Evaluative Criteria. The current edition, 1950, is in the process of being revised, and a new edition will be available in June 1960.

The General Committee of the Cooperative Study, made up of representatives of the regional associations of colleges and secondary schools, have approved the continuance of procedures and format of materials which characterized the 1950 edition with such changes as would be designed to clarify them and bring them up to date. To assist in this process national associations with specialized interests were asked to appoint committees to consider appropriate sections of the Evaluative Criteria and make suggestions for improvement. These committees were appointed; they worked on the assignment; and then they submitted their suggestions or had a representative at the revision workshop in Swarthmore durinig seven weeks of the summer of 1958 .

At the workshop, the specialist presented his suggestions to the other members who had other interests but were well acquainted with evaluation procedures. This process went on for a week with four to nine persons in the group. The level of interest throughout each week was high, and the results were generally recognized as good. All of the areas of the Evaluative Criteria were given this intensive study, and a first draft was ready at the end of the workshop. The work was progressive and cumulative; so some suggestions made in successive weeks have significance for

Roderic D. Matthews is Professor of Education in the University of Pennsylvania and Director of the Revision Program of the Cooperative Study of Secondary-School Standards, Philadelphia, Pennsylvania. 
areas considered earlier. The revising of these first drafts is now being done. Relatively little work was done on drafting the Manual, and that, too, is now being carried out. A draft copy of the 1960 edition of the Evaluative Criteria should be ready for review by the General Committee at its meeting in June 1959.

The personnel of the 1958 summer workshop at Swarthmore, Pennsylvania, was composed of 33 members representing many professional interests in the 1960 edition of the Evaluative Criteria. In the group were representatives from the U.S. Office of Education, eight state departments of education distributed from Maine to Alabama to Oregon, several city school systems, a number of senior high schools, several colleges of education, and subject area organizations including agricultural education, health and physical education, music education, religious education, and safety education. The members of the workshop were assigned to their areas of special interest covering all of the learning included in the 1960 edition of the Evaluative Criteria.

\section{HOW CAN THE PRINCIPAL BEST PROMOTE HIS PROFESSIONAL GROWTH AND THAT OF HIS STAFF?}

Chatrman: William E. McBride, Principal, Farragut High School, Chicago, Illinois.

\section{Discussants:}

Thomas R. Hornor, Assistant Superintendent in Charge of Secondary Education, Kanawha County Schools, Charleston, West Virginia.

Paul H. Farris, Principal, Pentucket Regional Junior-Senior High School, West Newbury, Massachusetts.

Summary of the presentation made by ALEXANDER A. MACKIMMIE, JR.

$\mathrm{T}$

HE principal who expects to be able to stimulate professional improvement on the part of his colleagues must first be sure that his own house is in order. He must leave no room for doubt as to the sincerity of his interest in and enthusiasm for this facet of his supervisory responsibility. It is also essential that his competency for furnishing leadership in this area be clearly recognized. These vital evidences that "he practices what he preaches" can be demonstrated only through a well-organized and consistent, personal, professional-improvement program.

Heading this program is that old stand-by, general and professional reading. The general category is mentioned first because it seems to the

\footnotetext{
Alexander A. Mackimmie, Jr., is Principal of Bulkeley High School, Hartford, Connecticut.
} 